\title{
Carotid-Sinus Baroreflex Modulation of Core and Skin Temperatures in Rats: An Open-Loop Approach
}

\author{
Dongmei ZHANG, Motonori ANDO, Fumiyasu YAMASAKI*, and Takayuki SATO \\ Department of Cardiovascular Control, and * Department of Clinical Laboratory, \\ Kochi Medical School, Nankoku, 783-8505 Japan
}

\begin{abstract}
The neural mechanisms of the thermoregulatory control of core and skin temperatures in response to heat and cold stresses have been well clarified. However, it has been unclear whether baroreceptor reflexes are involved in the control of core and skin temperatures. To investigate how the arterial baroreceptor reflex modulates the body temperatures, we examined the effect of pressure changes of carotid sinus baroreceptors on core and skin temperatures in halothane-anesthetized rats. To open the baroreflex loop and control arterial baroreceptor pressure (BRP), we cut vagal and aortic depressor nerves and isolated carotid sinuses. We sequentially altered BRP in $20-\mathrm{mmHg}$ increments from 60 to $180 \mathrm{mmHg}$ and then in $20-\mathrm{mmHg}$ decrements from 180 to $60 \mathrm{mmHg}$ while measuring
\end{abstract}

systemic arterial pressure (SAP), heart rate $(\mathrm{HR})$, and core blood temperature ( $\left.T_{\text {core }}\right)$ at the aortic arch and skin temperature $\left(T_{\text {skin }}\right)$ at the tail. In response to the incremental change in BRP by $120 \mathrm{mmHg}$, SAP, $\mathrm{HR}$, and $T_{\text {core }}$ fell by $90.3 \pm 5.1$ $\mathrm{mmHg}, \quad 60.3 \pm 10.5$ beats $\mathrm{min}^{-1}$, and $0.18 \pm$ $0.01^{\circ} \mathrm{C}$, respectively. $T_{\text {skin }}$ rose by $0.84 \pm 0.10^{\circ} \mathrm{C}$. The maximum rate of change per unit BRP change was $-2.1 \pm 0.2$ for SAP, $-1.5 \pm 0.4$ beats $\mathrm{min}^{-1} \mathrm{mmHg}^{-1}$ for $\mathrm{HR},-0.003 \pm 0.001^{\circ} \mathrm{C}$ $\mathrm{mmHg}^{-1}$ for $T_{\text {core }}$, and $0.011 \pm 0.002^{\circ} \mathrm{C} \mathrm{mmHg}^{-1}$ for $T_{\text {skin. }}$ After the administration of hexamethonium or bretylium, these baroreflexogenic responses were completely abolished. We concluded that $T_{\text {core }}$ and $T_{\text {skin }}$ are modulated by the arterial baroreceptor reflex. [The Japanese Journal of Physiology 53: 461-466, 2003]

Key words: baroreflex, open loop, temperature.

The sympathetic nervous system plays an important role in a short-term control of body temperature. The rate of heat transfer from the body interior to the surface is regulated by the sympathetic manipulation of the skin blood flow. The neural mechanisms of thermoregulatory control of skin temperature in response to heat and cold stresses have been clarified [1-3]. However, it has been unclear whether baroreceptor reflexes are involved in the control of skin temperature.

The neurophysiological studies indicated that electrical stimulation of the carotid sinus nerve [4] and the pharmacological modulation of arterial pressure [5] failed to change the skin sympathetic nerve activity. It is also indicated that carotid baroreceptor unloading had no effect on skin blood flow in humans [6]. On the other hand, there is literature demonstrating that hemorrhaging is clearly associated with cutaneous vasoconstriction through sympathetic activation in mice [7], rats [8-11], rabbits [12, 13], and dogs [14]. However, its mechanism for hemorrhage-induced skin vasoconstriction still remains controversial.

Earlier human studies showed that nonhypotensive lower body negative pressure increased the skin vascular resistance, suggesting the importance of the cardiopulmonary, and not arterial, baroreceptor reflex in the regulation of cutaneous vasomotor tone [15-17]. However, Ryan et al. [13] indicated that ear vascular resistance during caval occlusion-induced hypotension decreased in intact rabbits but not in sinoaortic-denervated rabbits, suggesting the crucial role of the arterial baroreceptor reflex in the regulation of ear blood flow and heat transfer to the ear.

The controversies on the role of the baroreceptor reflex in skin circulation and on the interaction between

Received on October 17, 2003; accepted on November 26, 2003

Correspondence should be addressed to: Takayuki Sato, Department of Cardiovascular Control, Kochi Medical School, Nankoku, 783-8505 Japan. Tel: +81-88-880-2309, Fax: +81-88-880-2310, E-mail: tacsato-kochimed@umin.ac.jp 
the baroreceptor and thermoregulatory reflexes would result from differences in experimental preparations. Although the effect of the cardiopulmonary baroreceptor reflex on thermoregulation was examined by the use of lower body negative pressure for unloading the cardiopulmonary baroreceptor, such a manipulation would inevitably produce changes in cardiac output according to the Frank-Starling law of the heart. Therefore it would be difficult to directly link the baroreceptor unloading to the resultant decrease in skin blood flow and temperature, because the decrease in cardiac output itself can directly modulate skin circulation. It is also difficult to evaluate the role of the arterial baroreceptor reflex in thermoregulation from the responses of core and skin temperatures to pharmacological changes in arterial pressure [18-20] because the systemic administration of vasoactive agents itself could affect the distribution of cardiac output to various organs, including the skin.

Along with thermoregulation, the baroreflex control of arterial pressure is a physiological feedback system. It is therefore complicated to clarify the effect of one regulatory system on another under experimental conditions in which the feedback loops of both systems are closed. In terms of systems physiology, an open-loop approach seems suitable for the elucidation of the effect of the baroreflex on thermoregulation. Our previous studies [21-24] developed experimental procedures for the isolation of arterial baroreceptor regions and equipment for the precise control of baroreceptor pressure in rats. In the present study, we characterized how the arterial baroreceptor reflex modulated core and skin temperatures under the open-loop conditions of the arterial baroreflex. We measured the central blood temperature at the ascending aorta as core temperature and monitored the skin temperature at the tail of the rat.

\section{METHODS}

Animals and surgical procedures. All experiments were performed in strict accordance with the Guiding Principles for the Care and Use of Animals in the Field of Physiological Science by the Physiological Society of Japan. Male Wistar rats (SLC, Hamamatsu, Japan) weighing 280-350 g were used. The temperature and humidity in an experimental room were continuously maintained in the ranges of $26-27^{\circ} \mathrm{C}$ and $40-45 \%$. After an induction of anesthesia, an endotracheal tube was introduced orally, and the rat was ventilated artificially via a volumecontrolled rodent respirator (model 693; Harvard Apparatus, South Natick, MA, USA). In accordance with
Ono et al. [25], the rat was anesthetized with inspiration of $1.2 \%$ halothane during surgical procedures and $0.6 \%$ halothane during data recording. For the measurement of systemic artery pressure (SAP), a polyethylene tubing (PE-50; Becton Dickinson, Parsippany, NJ, USA) was inserted into the right femoral artery. For the prevention of dehydration during experiments [26] and the elimination of spontaneous muscle activity, physiologic saline $\left(5 \mathrm{ml} \mathrm{kg}^{-1} \mathrm{~h}^{-1}\right)$ and pancuronium bromide $\left(0.8 \mathrm{mg} \mathrm{kg}^{-1} \mathrm{~h}^{-1}\right)$ was continuously administered into the left femoral vein with a syringe pump (CFV-3200; Nihon Kohden, Tokyo, Japan). The temperature of the infusate was kept at $37^{\circ} \mathrm{C}$ with an in-line heating system (SF-28; Warner Instruments, Hamden, CT, USA).

As described previously [23], we isolated bilateral carotid sinus baroreceptor regions. After the vagi and the aortic depressor nerves were cut, the external carotid arteries were briefly ligated at the root of the bifurcation of the common carotid arteries, and the internal carotid and pterygopalatine arteries were then embolized with two ball bearings of $0.8 \mathrm{~mm}$ diameter. Two short polyethylene tubes (PE-50) were placed into both carotid sinuses and connected to a fluidfilled transducer (DX-200; Viggo-Spectramed, Singapore) and to a custom-made servocontrolled pump system based on an electromagnetic shaker and power amplifier (ARB-126; AR Brown, Osaka, Japan). We used the servopump to impose any desired pressure on carotid sinus baroreceptors.

To measure the core temperature $\left(T_{\text {core }}\right)$, i.e., the central blood temperature, we placed a catheter-tip thermocouple (PTI-200; Unique Medical, Tokyo, Japan) in the ascending aorta via the right common carotid artery. To record the skin temperature $\left(T_{\text {skin }}\right)$, we put a plate type of thermoelectric couple (PTP-50; Unique Medical) on the surface of the tail, which was left exposed to room temperature. These two sensors were connected to a custom-made two-channel thermometer. The overall accuracy of repeated measurements in the range of $32-42^{\circ} \mathrm{C}$ was $\pm 0.01^{\circ} \mathrm{C}$. After all the incisions were closed in layers, the rat remained to be laid on a temperature-controlled heating pad (TR100; Fine Science Tools, North Vancouver, Canada) in a prone position during data recording. The surface of the pad was continuously kept at $37 \pm 0.1^{\circ} \mathrm{C}$.

Data recording. After the baseline SAP and $T_{\text {core }}$ became stable, we altered carotid-sinus baroreceptor pressure (BRP) sequentially in $20 \mathrm{mmHg}$ step increments from 60 to $180 \mathrm{mmHg}$, then in $20-\mathrm{mmHg}$ decrements from 180 to 60 by the servocontrolled pump. Each step was maintained for 2 minutes. The command signal to the pump was generated by a dedi- 
cated laboratory computer (PC-9801RA21; NEC, Tokyo, Japan) through a digital-to-analog converter (DA12-4-98; Contec, Osaka, Japan). The same cycle of sequential changes in BRP was repeated four times over $100 \mathrm{~min}$.

To clarify whether the arterial baroreflex control of $T_{\text {core }}$ and $T_{\text {skin }}$ was mediated through sympathetic efferents, we examined the effect of bretylium tosylate (12 $\mathrm{mg} \mathrm{kg}^{-1}$, I.V.) or hexamethonium $\left(30 \mathrm{mg} \mathrm{kg}^{-1}\right.$, I.V.).

The electrical signals of BRP, SAP, heart rate (HR), $T_{\text {core, }}$ and $T_{\text {skin }}$ were first low-pass filtered with antialiasing filters having a cutoff frequency of $100 \mathrm{~Hz}$ and an attenuation slope of $-80 \mathrm{~dB} /$ decade (ASIP0260L; Canopus, Kobe, Japan), then digitized at a rate of $200 \mathrm{~Hz}$ by means of an analog-to-digital converter (AD12-16D-98H; Contec).

Data analysis. A preliminary study indicated that the responses of SAP, HR, $T_{\text {core }}$, and $T_{\text {skin }}$ to each pressure step imposed on bilateral carotid sinus baroreceptors reached a steady state within $30 \mathrm{~s}$ (unpublished observation). Each steady-state value of the responses, therefore, was obtained by an averaging of the latter 30-s values during each pressure step of BRP. Finally, the responses of SAP, HR, $T_{\text {core }}$, and $T_{\text {skin }}$ to the same level of BRP in several cycles were averaged for each rat.

The relationship between $T_{\text {core }}$ and $T_{\text {skin }}$ during sequential changes in BRP was examined by a linear regression analysis.

To parametrically characterize the relationship between the input and output, we analyzed the data with a four-parameter logistic equation model [27]:

$$
y=p_{4}+p_{1} /\left[1+\exp \left\{p_{2}\left(x-p_{3}\right)\right\}\right]
$$

where $y$ is the output and $x$ is the input. The four parameters are defined as follows: $p_{1}$, the range of change in $y$ (i.e., maximum-minimum values of $y$ ); $p_{2}$, the coefficient for a calculation of gain; $p_{3}$, the value of $x$ corresponding to the midpoint over the range of $y$; and $p_{4}$, the minimum value of $y$. The instantaneous gain was also calculated from the first derivative of the logistic function, and the maximum gain is $-p_{1} p_{2} / 4$ at $x=p_{3}$.

The differences in paired measurements under two conditions were tested by paired $t$-tests. They were considered significant at $p<0.05$. The values are expressed as means $\pm \mathrm{SD}$.

\section{RESULTS}

A representative example of the original tracings of BRP, SAP, HR, $T_{\text {core }}$, and $T_{\text {skin }}$ during 4 cycles of se- quential changes in BRP from 60 to $180 \mathrm{mmHg}$ and back again is shown in Fig. 1. Each response of SAP, $\mathrm{HR}, T_{\text {core }}$, and $T_{\text {skin }}$ to a given input appears to be reproducible during the whole recording procedure. A representative relationship between $T_{\text {core }}$ and $T_{\text {skin }}$ during a cycle of the sequential changes in BRP from 60 to $180 \mathrm{mmHg}$ and back again is shown in Fig. 2. Although $T_{\text {core }}$ was inversely correlated with $T_{\text {skin, }}$, the trajectory of the $T_{\text {core }}-T_{\text {skin }}$ point displayed a hystere-

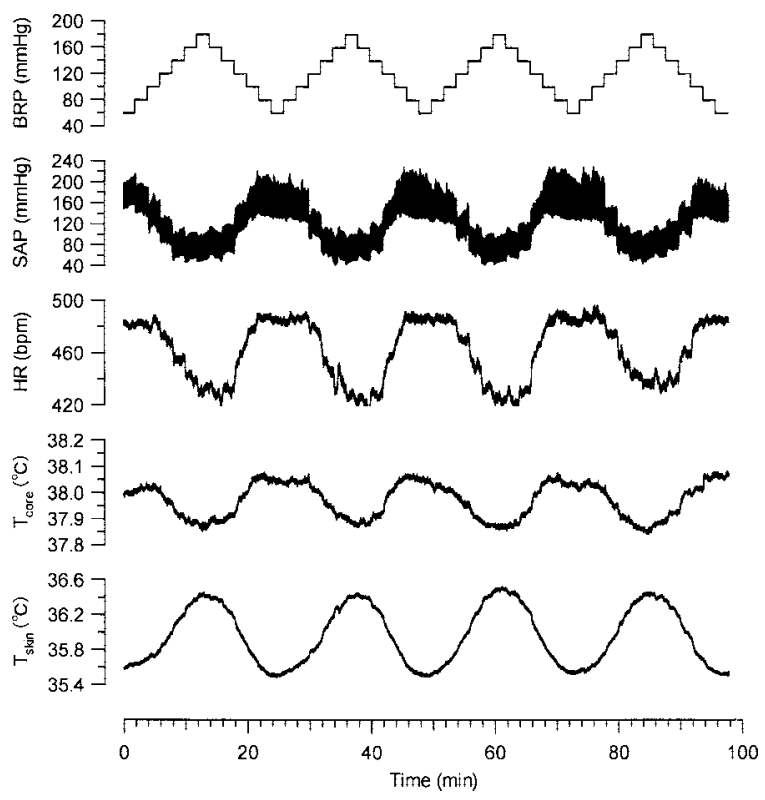

Fig. 1. Original tracings of carotid-sinus baroreceptor pressure (BRP), systemic artery pressure (SAP), heart rate (HR), core temperature ( $\left.T_{\text {core }}\right)$, and skin temperature ( $\left.T_{\text {skin }}\right)$ during 4 cycles of sequential changes in BRP from 60 to $180 \mathrm{mmHg}$ and back again. The responses of SAP, HR, $T_{\text {core }}$, and $T_{\text {skin }}$ to a given input appeared to be consistent throughout the whole recording period.

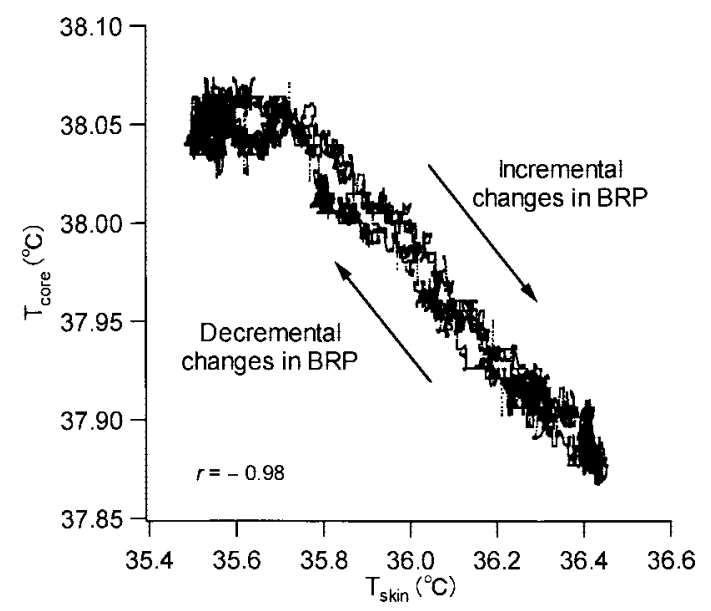

Fig. 2. Graph showing the relationship between core ( $\left.T_{\text {core }}\right)$ and skin temperatures ( $\left.T_{\text {skin }}\right)$ during a cycle of the sequential changes in carotid-sinus baroreceptor pressure from 60 to $180 \mathrm{mmHg}$ and back again. $r$, correlation coefficient. See text for details. 
A

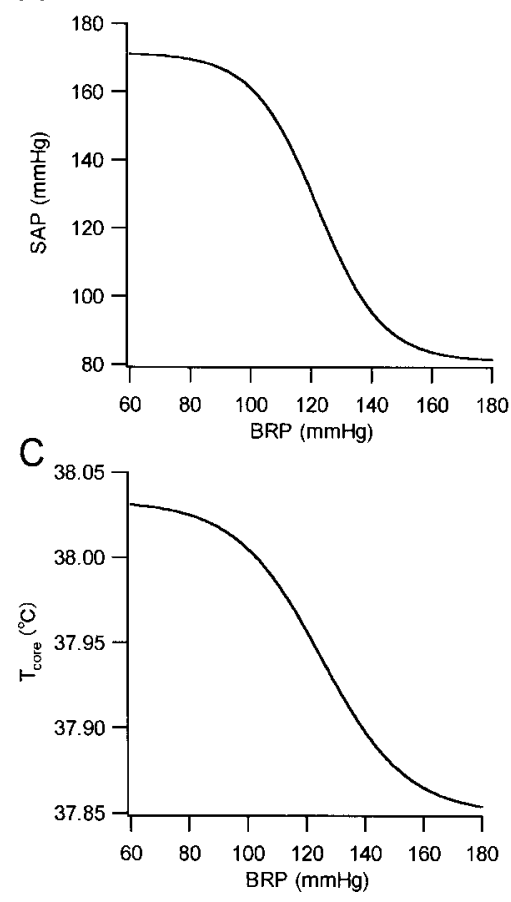

B
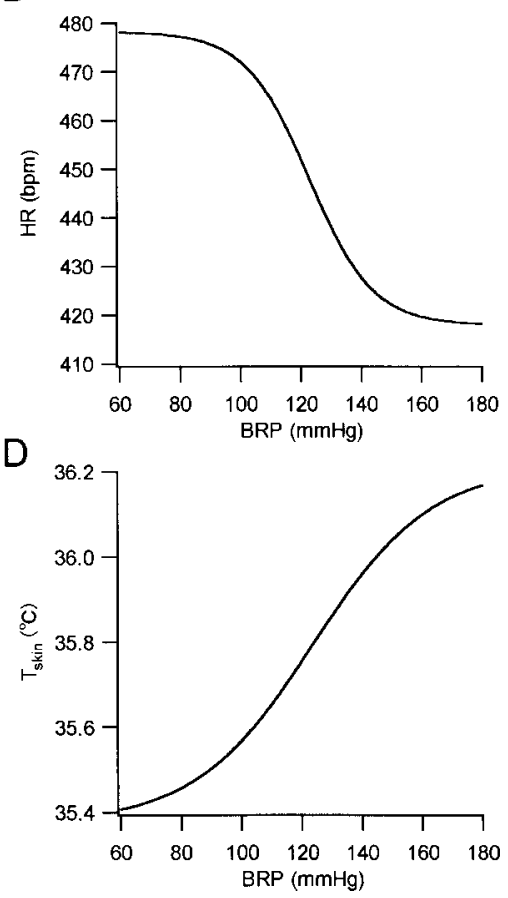

Fig. 3. Graphs showing the relationship of systemic arterial pressure (SAP, A), heart rate (HR, B), core temperature ( $\left.T_{\text {core }}, \mathrm{C}\right)$, and skin temperature $\left(T_{\text {skin }}, \mathrm{D}\right)$ against carotid-sinus baroreceptor pressure (BRP). Each curve was constructed with the mean values of the parameters of the logistic regression analysis shown in Table 1. See text for details.

Table 1. Four-parameter logistic regression analysis of the relationships of SAP, HR, $T_{\text {core, }}$ and $T_{\text {skin }}$ against BRP.

\begin{tabular}{|c|c|c|c|c|}
\hline & SAP & $\mathrm{HR}$ & $T_{\text {core }}$ & $T_{\text {skin }}$ \\
\hline$p_{1}$ & $90.3 \pm 5.1 \mathrm{mmHg}$ & $60.3 \pm 10.5$ beats $\mathrm{min}^{-1}$ & $0.18 \pm 0.01^{\circ} \mathrm{C}$ & $0.84 \pm 0.10^{\circ} \mathrm{C}$ \\
\hline$p_{2}$ & $0.093 \pm 0.013 \mathrm{mmHg}^{-1}$ & $0.095 \pm 0.010 \mathrm{mmHg}^{-1}$ & $0.069 \pm 0.005 \mathrm{mmHg}^{-1}$ & $-0.051 \pm 0.012 \mathrm{mmHg}^{-1}$ \\
\hline$p_{3}$ & $122.1 \pm 1.6 \mathrm{mmHg}$ & $122.7 \pm 2.4 \mathrm{mmHg}$ & $125.0 \pm 1.4 \mathrm{mmHg}$ & $123.5 \pm 2.9 \mathrm{mmHg}$ \\
\hline$p_{4}$ & $81.1 \pm 7.4 \mathrm{mmHg}$ & $418.8 \pm 16.5$ beats $\min ^{-1}$ & $37.85 \pm 0.23^{\circ} \mathrm{C}$ & $35.38 \pm 1.08^{\circ} \mathrm{C}$ \\
\hline
\end{tabular}

See the METHODS section for the definition of parameters $p_{1}-p_{4}$. SAP, systemic arterial pressure; HR, heart rate; $T_{\text {core, }}$ core temperature; $T_{\text {skin, }}$ skin temperature; BRP, and carotid-sinus baroreceptor pressure. Values are means $\pm S D$ for 8 rats.

sis loop. During the incremental change in BRP, the decremental change in $T_{\text {core }}$ was preceded by the incremental change in $T_{\text {skin. }}$. These characteristics were observed for all the data. The correlation coefficient was $-0.97 \pm 0.01$ for 8 rats. The results of the four-parameter logistic regression analysis of the carotid sinus baroreflex control of SAP, HR, $T_{\text {core, }}$ and $T_{\text {skin }}$ from 8 rats are summarized in Table 1 . In response to the incremental change in BRP by $120 \mathrm{mmHg}$, SAP, HR, and $T_{\text {core }}$ fell by $90.3 \pm 5.1 \mathrm{mmHg}, 60.3 \pm 10.5$ beats $/ \mathrm{min}$, and $0.18 \pm 0.01^{\circ} \mathrm{C}$, respectively, but $T_{\text {skin }}$ rose by $0.84 \pm 0.10^{\circ} \mathrm{C}$. The maximum rates of change per unit BRP change were $-2.1 \pm 0.2$ for SAP, $-1.5 \pm 0.4$ beats $\mathrm{min}^{-1} \mathrm{mmHg}^{-1}$ for $\mathrm{HR},-0.003 \pm$ $0.0005^{\circ} \mathrm{C} \mathrm{mmHg}^{-1}$ for $T_{\text {core }}$, and $0.01 \pm 0.002^{\circ} \mathrm{C}$ $\mathrm{mmHg}^{-1}$ for $T_{\text {skin. }}$. The values of $p_{3}$ were $122.1 \pm$ $1.6 \mathrm{mmHg}$ for SAP, $122.7 \pm 2.5 \mathrm{mmHg}$ for $\mathrm{HR}$, $125.0 \pm 1.4 \mathrm{mmHg}$ for $T_{\text {core, }}$ and $123.5 \pm 3.0 \mathrm{mmHg}$ for $T_{\text {skin. }}$. There was no significant difference in $p_{3}$ among them. We then constructed the averaged curves of the sigmoid responses of SAP, HR, $T_{\text {core }}$, and $T_{\text {skin }}$ to the BRP (Fig. 3) from mean values for parameters $p_{1}-p_{4}$ shown in Table 1.

After the administration of bretylium or hexamethonium, the baroreflex modulation of $T_{\text {core }}$ and $T_{\text {skin }}$ was completely abolished (Fig. 4).

\section{DISCUSSION}

The present study showed that the baroreflex openloop analysis yields BRP- $T_{\text {core }}$ and BRP- $T_{\text {skin }}$ curves with sigmoid shapes. In response to incremental changes in carotid sinus BRP, $T_{\text {core }}$ decreased, but $T_{\text {skin }}$ increased. The maximum gains of the carotid sinus baroreflex control of SAP, HR, $T_{\text {core }}$, and $T_{\text {skin }}$ occurred at the similar level of BRP in normothermic environments.

Baroreflexogenic changes in $T_{\text {core }}$ and $T_{\text {skin. }}$ The flow of blood to the skin is the most effective mechanism for heat transfer from the body core to the 


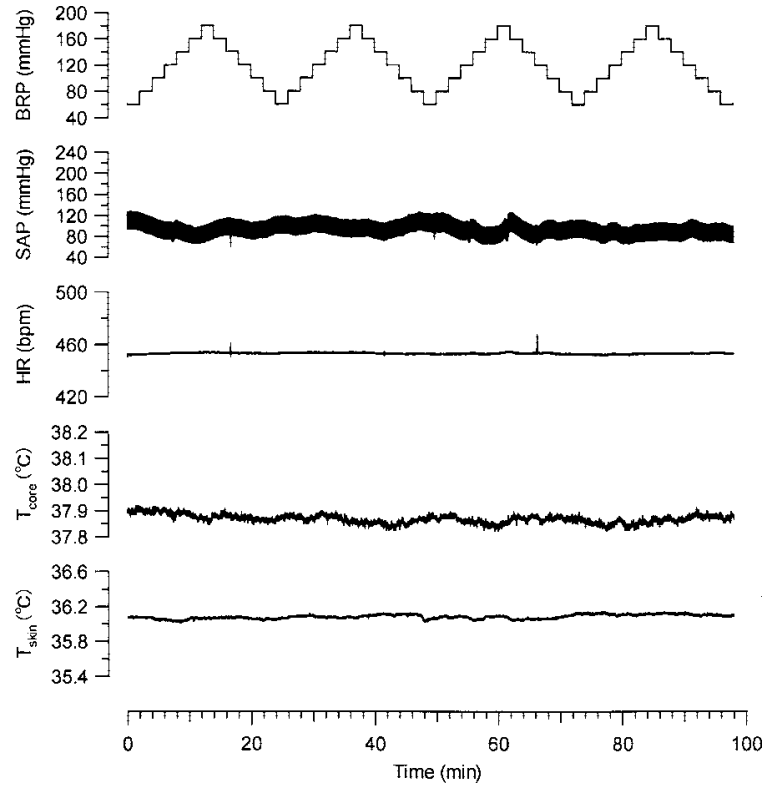

Fig. 4. Original tracings of carotid-sinus baroreceptor pressure (BRP), systemic artery pressure (SAP), heart rate (HR), core temperature ( $\left.T_{\text {core }}\right)$, and skin temperature $\left(T_{\text {skin }}\right)$ during 4 cycles of sequential changes in BRP from 60 to $180 \mathrm{mmHg}$ and back again after the administration of bretylium tosylate $\left(12 \mathrm{mg} \mathrm{kg}^{-1}, \mathrm{I.V}\right.$.).

skin. An increase in the skin blood flow causes both a decrease in $T_{\text {core }}$ and an increase in $T_{\text {skin. }}$. The vasculature of human and nonhuman skins responds to various regulatory reflexes, including those of thermoregulatory and baroreceptor origins [2,3]. Previous reports suggested that the response of cutaneous circulation to the baroreflex was attributed to cardiopulmonary baroreceptors in humans $[3,15,16]$. In our study, to exclude the participation of the low-pressure baroreceptors of cardiopulmonary regions and to investigate the effect of the arterial baroreceptor on $T_{\text {skin, }}$, we cut both vagal nerves and imposed pressure perturbations only on arterial baroreceptors in carotid sinuses. Our results clearly indicated the significant effect of the arterial baroreflex on $T_{\text {skin }}$; the increase in arterial BRP caused the increase in $T_{\text {skin. }}$ Thus the arterial baroreceptor reflex is believedto participate in the regulation of cutaneous vasculature. The inverse relationship between $T_{\text {core }}$ and $T_{\text {skin }}$ reflected the significant role of the blood flow to the skin in the regulation of body temperature. To our knowledge, this is the first report to demonstrate that both $T_{\text {core }}$ and $T_{\text {skin }}$ are affected by the arterial baroreceptor reflex.

The baroreflex control of the sympathoadrenal system could affect $T_{\text {core }}$ and $T_{\text {skin }}$ through chemical thermogenesis. However, it is reported that the change in body temperature appeared $2-3 \mathrm{~min}$ after the chemical thermogenesis [28]; on the other hand, our data showed that the response of body temperature to a given level of BRP more rapidly reached its steady state within 1-2 min. The inverse relationship between $T_{\text {core }}$ and $T_{\text {skin }}$ would support the mechanism of heat transfer from the core to the surface rather than the chemical thermogenesis mechanism. From the result that hexamethonium or bretylium diminished the baroreflexogenic change, the major pathway of its efferent limb of the reflex is believed to be the sympathetic nervous system.

Open-loop approach. If arterial pressure is elevated by an external perturbation, the neurogenic vasoconstrictor activity is decreased by the arterial baroreflex. Thereafter $T_{\text {skin }}$ increases and $T_{\text {core }}$ decreases because of the increase in skin blood flow. This decrease in $T_{\text {core }}$ would be sensed by central thermoreceptors $[29,30]$, and the thermoregulatory center would command the suppression of the skin vasodilatation. Thus the response of $T_{\text {skin }}$ to the change in arterial BRP should be attenuated while the central thermoregulatory reflex is functioning. The baroreflexogenic change in $T_{\text {skin, }}$, therefore, could be underestimated. These aspects indicate difficulty in the quantitative evaluation of the interaction of the physiological feedback systems under closed-loop conditions. In the present study, we could make an open-loop analysis of the effect of the baroreflex on $T_{\text {core }}$ and $T_{\text {skin, }}$, and the thermoreflex loop remained closed.

Earlier studies investigated the effect of the arterial baroreflex on body temperatures under the closedloop conditions of the arterial baroreflex [18-20]. However, vasoactive agents used in these studies for loading or unloading the arterial baroreceptors could directly, i.e., not mediated by the arterial baroreflex, affect the distribution of cardiac output. Thus our approach would be more suitable for clarifying the effect of the arterial baroreflex on body temperatures.

In conclusion, we examined the effect of the arterial baroreflex on core and skin temperatures in halothaneanesthetized rats. To open the baroreflex loop and control BRP, we isolated carotid sinuses. We sequentially altered BRP from 60 to $180 \mathrm{mmHg}$ while measuring SAP, HR, $T_{\text {core }}$, and $T_{\text {skin. }}$. In response to the incremental BRP change, SAP, HR, and $T_{\text {core }}$ fell, but $T_{\text {skin }}$ rose. After the administration of hexamethonium or bretylium, these baroreflexogenic responses were completely abolished. We concluded that $T_{\text {core }}$ and $T_{\text {skin }}$ are modulated by the arterial baroreceptor reflex.

This study was supported by research grants from Uehara Memorial Foundation, Suzuken Memorial Foundation, Tateisi Science and Technology Foundation, and Mochida Memorial Foundation. 


\section{REFERENCES}

1. Fox RH and Edholm OG: Nervous control of the cutaneous circulation. Br Med Bull 19: 110-114, 1963

2. Rowell LB: Reflex control of the cutaneous vasculature. J Invest Dermatol 69: 154-166, 1977

3. Johnson JM, Brengelmann GL, Hales JRS, Vanhoutte PM, and Wenger CB: Regulation of the cutaneous circulation. Fed Proc 45: 2841-2850, 1986

4. Wallin BG, Sundolf G, and Delius W: The effect of carotid sinus nerve stimulation on muscle and skin sympathetic nerve activity in man. Pflügers Arch 358: 101-110, 1975

5. Wilson TE, Cui J, and Crandall CG: Absence of arterial baroreflex modulation of skin sympathetic activity and sweat rate during whole-body heating in humans. J Physiol (Lond) 536: 615-623, 2001

6. Crandall CG, Johnson JM, Kosiba WA, and Kellogg DL $\mathrm{Jr}$ : Baroreceptor control of the cutaneous active vasodilator system. J Appl Physiol 81: 2192-2198, 1996

7. Wang P, Ba ZF, Burkhardt J, and Chaudry IH: Traumahemorrhage and resuscitation in the mouse: effects on cardiac output and organ blood flow. Am J Physiol 264: $\mathrm{H} 1164-\mathrm{H} 1173,1993$

8. Sapirstein LA, Sapirstein EH, and Bredemeyer A: Effect of hemorrhage on the cardiac output and its distribution in the rat. Circ Res 8: 135-148, 1960

9. Takacs L, Kallay K, and Skolnik JH: Effect of tourniquet shock and acute hemorrhage in the circulation of various organs in the rat. Circ Res 10: 753-757, 1962

10. Pang CCY: Effects of vasopressin antagonist and saralasin in regional blood flow following hemorrhage. Am J Physiol 245: H749-H755, 1983

11. O'Leary DS and Johnson JM: Baroreflex control of the rat tail circulation in normothermia and hyperthermia. J Appl Physiol 66: 1234-1241, 1989

12. Neutze JM, Wyler F, and Rudolph AM: Changes in distribution of cardiac output after hemorrhage in rabbits. Am J Physiol 215: 857-864, 1968

13. Ryan KL, Fred Taylor W, and Bishop VS: Arterial Baroreflex modulation of heat-induced vasodilation in the rabbit ear. J Appl Physiol 83: 2091-2097, 1997.

14. Bond RF, Lackey GF, Taxis JA, and Green HD: Factors governing cutaneous vasoconstriction during hemorrhage. Am J Physiol 219: 1210-1215, 1970

15. Abboud FM, Eckerberg DL, Johannsen UT, and Mark AL: Carotid and cardiopulmonary baroreceptor control of splanchnic and forearm vascular resistance during venous pooling in man. J Physiol (Lond) 286: 173-184, 1979

16. Tripathi A and Nadel ER: Forearm skin and muscle vasoconstriction during lower body negative pressure.
J Appl Physiol 60: 1535-1541, 1986

17. Kellogg DL Jr, Johnson JM, and Kostra WA: Baroreflex control of the cutaneous active vasodilator system in humans. Circ Res 66: 1420-1426, 1990

18. Shibata $\mathrm{H}$ : Baroreflex suppression of nonshivering thermogenesis in rats. Jpn J Physiol 32: 937-944, 1982

19. Nunomura $T$, Nagasaka $T$, and Shibata $H$ : Effects of restraint on baroreflex sensitivity in altering heart rate and heat production in rats. Jpn J Physiol 33: 667-670, 1983

20. Shido $O$ and Nagasaka T: Effects of intraventricular neurotensin on blood pressure and heat balance in rats. Jpn J Physiol 35: 311-320, 1985

21. Sato T, Kawada T, Inagaki M, Shishido T, Sugimachi M, and Sunagawa K: Dynamics of sympathetic baroreflex control of arterial pressure in rats. Am J Physiol 285: R262-R270, 2003

22. Sato $T$, Kawada $T$, Inagaki $M$, Shishido $T$, Takaki $H$, Sugimachi M, and Sunagawa K: New analytic framework for understanding sympathetic baroreflex control of arterial pressure. Am J Physiol 276: H2251-H2261, 1999

23. Sato $T$, Kawada $T$, Miyano $H$, Shishido $T$, Inagaki $M$, Yoshimura R, Tatewaki T, Sugimachi M, Alexander J Jr, and Sunagawa K: New simple methods for isolating baroreceptor regions of carotid sinus and aortic depressor nerves in rats. Am J Physiol 276: H326-H332, 1999

24. Sato T, Kawada T, Sugimachi M, and Sunagawa K: Bionic technology revitalizes native baroreflex function in rats with baroreflex failure. Circulation 106: 730-734, 2002

25. Ono A, Kuwaki T, Kumada M, and Fujita T: Differential central modulation of the baroreflex by salt loading in normotensive and spontaneously hypertensive rats. Hypertension 29: 808-814, 1997

26. Dibona GF and Sawin LL: Reflex regulation of renal nerve activity in cardiac failure. Am J Physiol 226: R27R39, 1994

27. Kent BB, Drane JW, Blumenstein B, and Manning JW: A mathematical model to assess changes in the baroreceptor reflex. Cardiology 57: 295-310, 1972

28. Nedergaard $\mathrm{J}$ and Lindberg $\mathrm{O}$ : The brown fat cell. Int Rev Cytol 74: 187-286, 1982

29. Wyss CR, Brengelmann GL, Johnson JM, Rowell LB, and Silverstein D: Altered control of skin blood flow at high skin and core temperatures. J Appl Physiol 38: 839-845, 1975

30. Nakajima $Y$, Mizobe T, Takamata $A$, and Tanaka $Y$ : Baroreflex modulation of peripheral vasoconstriction during progressive hypothermia in anesthetized humans. Am J Physiol 279: R1430-R1436, 2000 